\title{
Risk Factors for New Vertebral Fracture After Percutaneous Vertebroplasty for Osteoporotic Vertebral Compression Fractures
}

\author{
Zi-Long Zhang ${ }^{1,2, *}$ \\ Jun-Song Yang ${ }^{1} * *$ \\ Ding-Jun $\mathrm{Hao}^{\prime}$ \\ Tuan-Jiang Liu' \\ Qi-Ming Jing ${ }^{2, *}$ \\ 'Department of Spine Surgery, Honghui \\ Hospital, Xi'an Jiaotong University, Xi'an, \\ Shaanxi, People's Republic of China; \\ ${ }^{2}$ Graduate School of Xi'an Medical \\ University, Xi'an, Shaanxi, People's \\ Republic of China \\ *These authors contributed equally to \\ this work
}

Correspondence: Ding-Jun Hao,

Department of Spine Surgery, HongHui

Hospital, Xi'an Jiaotong University, Xi'an

City, Shaanxi Province, People's Republic

of China

Email168404760I@qq.com
Purpose: To analyze the risk factors for new vertebral fractures after percutaneous vertebroplasty (PVP) for osteoporotic vertebral compression fractures (OVCFs).

Patients and Methods: We retrospectively reviewed the records of patients with symptomatic OVCFs who underwent PVP in our hospital, from January 2014 to January 2019. Demographic and lifestyle data on the presence of underlying chronic disease, preoperative bone mineral density, details of vertebral fractures, postoperative osteoporosis treatment, and new fracture development were collected. Patients were divided into postoperative fracture and non-fracture groups. To identify the independent risk factors for new vertebral fracture development, variables significant on univariate analysis were included in a multivariate regression model.

Results: Of the 2202 patients treated with PVP, 362 (16.43\%) had a new postoperative vertebral fracture. All patients were followed up for $>12$ months (mean 14.7 months). Univariate analysis revealed no significant difference in height; body weight; preoperative bone mineral density; number of fractured vertebrae; injection volume of bone cement in a single vertebra; leakage rate of bone cement; or presence of hypertension, coronary heart disease, and chronic obstructive pulmonary disease between the fracture and non-fracture groups $(\mathrm{P}>0.05)$. Age, sex, smoking, alcohol consumption, diabetes mellitus, postoperative exercise, and postoperative osteoporosis treatment were associated with new vertebral fractures (all $\mathrm{P}<0.05$ ). A multivariate analysis showed that age (odds ratio $[\mathrm{OR}]=1.212$, $\mathrm{P}<0.0001)$, female sex $(\mathrm{OR}=1.917, \mathrm{P}<0.0001)$, smoking $(\mathrm{OR}=1.538, \mathrm{P}=0.026)$, and diabetes $(\mathrm{OR}=1.915, \mathrm{P}<0.0001)$ were positively correlated with new vertebral fracture development, whereas postoperative exercise $(\mathrm{OR}=0.220, \quad \mathrm{P}<0.0001)$ and osteoporosis treatment $(\mathrm{OR}=0.413, \mathrm{P}<0.0001)$ were negatively correlated.

Conclusion: Elderly patients, females, and those with a history of smoking and diabetes are at high risk of new vertebral fracture after PVP. Patients should be encouraged to stop smoking and consuming alcohol, control blood glucose level, participate in sufficient physical activity, and adhere to osteoporosis treatment to prevent new vertebral fractures.

Keywords: aged, fractures, compression, osteoporosis, risk factors, spinal fractures, vertebral body

\section{Introduction}

Osteoporosis is a progressive disease of bone loss that gradually develops with aging. ${ }^{1}$ Although the onset is insidious, the potential for harm is great. Frequently, falls or injuries lead to osteoporotic fractures in the elderly, among which spinal thoracolumbar fractures 
are the most common. ${ }^{2}$ Since its development in 1987, percutaneous vertebroplasty (PVP) can effectively relieve pain and recover vertebral body height, with minimal trauma and quick recovery time; it has become the treatment of choice in osteoporotic vertebral compression fractures (OVCFs). ${ }^{3,4}$ Postoperatively, there is a high incidence of developing a new vertebral fracture, a long-term complication of PVP. The incidence of new fracture development in patients aged under 80 years is reportedly $9 \%$, whereas, it is $33 \%$ for those aged over 80 years. ${ }^{5}$ Studies have confirmed that sex, age, and bone cement-related factors influence the development of new vertebral fractures after PVP. ${ }^{6}$ As osteoporosis is closely related to lifestyle factors, such as smoking, alcohol consumption, and physical activity, it is thought that these same factors will affect the incidence of new vertebral fractures postoperatively. However, no definitive evidence is available to support this theory. Indeed, it is unclear whether treatment of lifestylerelated factors will reduce the incidence of new vertebral fracture development. In this study, based on a large dataset from our hospital, the risk factors for the development of a new vertebral fracture in patients with OVCFs after PVP were explored by multi-factor regression analysis.

\section{Materials and Methods}

This was a retrospective cohort study, which included 2202 inpatients who underwent PVP for symptomatic OVCFs at our hospital over a 5-year period, from January 2014 to January 2019. We reviewed each patient's clinical records and extracted information onto a prearranged database.

\section{Inclusion Criteria}

The inclusion criteria were as follows: 1) preoperative magnetic resonance imaging (MRI) confirming an OVCF and fat suppression imaging showing high-signal intensity in the fractured vertebral body; 2) PVP; 3) bone mineral density $\mathrm{T}$ score $\leq-2.5$, as measured by preoperative dualenergy X-ray; 4) follow-up time $>1$ year; and 5) complete clinical and imaging data.

\section{Exclusion Criteria}

The exclusion criteria were as follows: 1) symptomatic low back and leg pain caused by other reasons (disc herniation, vertebral spondylolisthesis, spondylolysis, and others), 2) infectious diseases, 3) a malignant spinal tumor, 4) paralysis or inability to move autonomously, and 5) an unwillingness to return for follow-up visits.
Patients were followed up regularly at $1,3,6$, and 12 months after surgery. After 12 months, doctors decided whether to extend the review time according to the degree of recovery of patients. A thoracolumbar X-ray examination was performed during the review. If the patient had a sudden onset of back pain during the follow-up period, X-ray imaging and MRI were performed to determine the occurrence of a new vertebral fracture. The criteria for the development of a new postoperative vertebral fracture included recurrent back pain after PVP; percussion pain occurring at corresponding segments; and fat suppression T2-weighted MRI showing a high-signal intensity of the fractured vertebral body, with or without a vertebral compression fracture. ${ }^{7}$

The following information was recorded for each patient: basic demographic data (sex, age, height, and weight), preoperative bone mineral density (absolute values), the number of vertebral body fractures, a single vertebral body bone cement injection, bone cement leakage rate, lifestyle-related factors (smoking, drinking, and postoperative exercise), and presence of chronic diseases (hypertension, diabetes, coronary atherosclerosis, and chronic obstructive pulmonary disease). At each postoperative review, the patients were asked whether they followed the doctor's advice to exercise and whether they had undergone osteoporosis treatment.

Exercise was defined as aerobic exercise, including brisk walking, jogging, dancing, swimming, and climbing, that increased the heart rate for at least $30 \mathrm{~min}$ and was performed for a minimum of four times a week.

Medications for osteoporosis treatment included calcitonin and bisphosphonates. According to the treatment plan prescribed by the doctor at discharge, during the review period, medication was to be taken regularly according to the treatment course (including calcitonin and bisphosphonates used in our hospital) for at least 12 months.

\section{Statistical Methods}

Continuous data are expressed as means \pm standard deviations, and the independent samples $t$-test was used for comparison between groups. Categorical data were analyzed by a chi-square test. A univariate analysis was used to identify potential influencing factors for new vertebral fracture after PVP. A multivariate logistic regression analysis was conducted using the variables with statistical significance in the univariate analysis. All statistical analyses were performed using SPSS Statistics for Windows, version 23.0 (IBM Corp, Armonk, NY, USA). A P value of $<0.05$ was considered statistically significant. 


\section{Results}

In this study, a total of 2202 patients were followed up for at least 12 months, with an average follow-up time of 14.7 months. These included 569 males, aged 55-82 years (mean $=67$ years), and 1633 females, aged $52-84$ years (mean $=64$ years). Patients' demographic details are shown in Table 1. Among the total participants, 362 patients with a new postoperative vertebral fracture $(16.43 \%)$ were classified as the fracture group, while the remaining 1840 patients with no new postoperative vertebral fracture were classified as the non-fracture group.

\section{Univariate Analysis}

There was no significant difference in height and weight between the fracture and non-fracture groups $(\mathrm{P}>0.05)$, as well as in absolute preoperative bone mineral density, number of fractured vertebrae, injection volume of bone cement in a single vertebra, and leakage of bone cement (all $\mathrm{P}>0.05$ ). In terms of hypertension, coronary heart disease, chronic obstructive pulmonary disease, and other complications, there was no statistical significance in the proportion of patients between the two groups $(\mathrm{P}>0.05)$.

The mean age of the fracture group was significantly higher than that of the non-fracture group, $(\mathrm{t}=-14.020$, $\mathrm{P}<0.0001)$; the proportion of female patients in the fracture group (83.1\%) was significantly higher than that in the non-fracture group $\left(72.4 \% ; x^{2}=18.268, \mathrm{P}<0.0001\right)$; the percentage of smokers in the fracture group $(15.2 \%)$ was significantly higher than that in the non-fracture group $\left(10.2 \% ; x^{2}=7.825, \mathrm{P}=0.005\right)$; the proportion of alcohol drinkers in the fracture group (12.7\%) was significantly higher than that in the non-fracture group $\left(8.3 \% ; x^{2}=7.098\right.$, $\mathrm{P}=0.008$ ); the percentage of diabetic patients in the fracture group (30.1\%) was significantly higher than that in the non-fracture group $\left(22.9 \% ; x^{2}=8.511, \mathrm{P}=0.004\right)$; the proportion of people performing adequate exercise postoperatively in the fracture group (47.2\%) was significantly lower than that in the non-fracture group $(81.9 \%$; $x^{2}=200.444, \mathrm{P}<0.0001$ ); and the proportion of patients in the fracture group undergoing osteoporosis treatment (21.3\%) was significantly lower than that in the nonfracture group $\left(39.7 \% ; x^{2}=44.125, \mathrm{P}<0.0001\right)$. Table 1 shows the results of the univariate analysis.

\section{Multivariate Analysis}

The independent risk factors that positively correlated with new fracture development after PVP were as follows: age (odds ratio $[\mathrm{OR}]=1.212,95 \%$ confidence interval $[\mathrm{CI}]=1.174-1.252, \mathrm{P}<0.0001)$, female sex $(\mathrm{OR}=1.917,95 \%$ $\mathrm{CI}=1.379-2.665, \quad \mathrm{P}<0.0001)$, smoking $\quad(\mathrm{OR}=1.538,95 \%$ $\mathrm{CI}=1.054-2.245, \mathrm{P}=0.026)$, and diabetes $(\mathrm{OR}=1.915,95 \%$ $\mathrm{CI}=1.438-2.551, \quad \mathrm{P}<0.0001) . \quad$ Postoperative exercise $(\mathrm{OR}=0.220,95 \% \mathrm{CI}=0.169-0.286, \mathrm{P}<0.0001)$ and osteoporosis treatment $(\mathrm{OR}=0.413,95 \% \mathrm{CI}=0.305-0.560, \mathrm{P}<0.0001)$ were negatively correlated with new vertebral fracture development after PVP. Table 2 and Figure 1 show the results of multivariate analysis.

\section{Discussion}

As a surgical treatment for OVCFs, PVP is easy to perform and has a good analgesic effect. As a common complication of PVP, new vertebral fracture development is a troublesome concern for patients and clinicians. Many factors, including sex, age, diffusion of bone cement, and lifestyle factors, may influence this complication. ${ }^{5,6}$ Osteoporosis is a chronic progressive disease that is hidden, and in the absence of external intervention, it is unlikely to improve as it is difficult to rely on bones healing independently. ${ }^{8}$ A good healing environment postoperatively is exacerbated by chronic diseases, their treatments, and lifestyle factors. We expanded the search for independent risk factors for new vertebral fractures after PVP by including factors, such as bone cement leakage and volume status, presence of smoking and alcohol consumption, presence of chronic disease, postoperative osteoporosis treatment, and adequate postoperative exercise. Significant factors for the development of new vertebral fractures included age, sex, smoking and alcohol consumption, presence of diabetes, adequate postoperative exercise, and postoperative osteoporosis treatment.

\section{Age and Sex}

Age is an important factor affecting the degree of osteoporosis, and bone mass loss increases gradually with age. Warden et $\mathrm{al}^{9}$ argued that the main reason for bone loss with increasing age is a gradual reduction in calcium intake, with increased excretion of calcium. This results in lower serum calcium level and a secondary increase in parathyroid hormone level, leading to decreased bony calcium deposition. In our study, increasing age was a risk factor for new vertebral fracture development after PVP. Similarly, female sex was also an independent risk factor, mainly related to the unique physiology of women. In postmenopausal women, estrogen loss alters bone metabolism by increasing osteoclast activity, resulting in 
Table I Univariate Analysis of New Vertebral Fracture After Vertebroplasty

\begin{tabular}{|c|c|c|c|c|}
\hline & $\begin{array}{l}\text { Fracture Group } \\
(n=362)(\%)\end{array}$ & $\begin{array}{l}\text { Non-Fracture Group } \\
(1840)(\%)\end{array}$ & $t / x^{2}$ value & $P$ value \\
\hline Age (yrs) & $69.32 \pm 4.426$ & $65.80 \pm 4.045$ & -14.020 & 0.000 \\
\hline $\operatorname{Sex}(\%)$ & & & 18.268 & 0.000 \\
\hline Male & $61(16.9)$ & $508(27.6)$ & & \\
\hline Female & $301(83.1)$ & I332 (72.4) & & \\
\hline Height $(\mathrm{cm})$ & $159.75 \pm 8.386$ & $158.94 \pm 8.737$ & -1.635 & 0.102 \\
\hline Body weight $(\mathrm{kg})$ & $59.74 \pm 8.623$ & $59.32 \pm 6.710$ & -0.879 & 0.380 \\
\hline Preoperative bone mineral density $(\mathrm{kg} / \mathrm{cm} 3)$ & $3.259 \pm 0.4094$ & $3.220 \pm 0.4169$ & -1.619 & 0.106 \\
\hline Number of fractured vertebrae & $1.31 \pm 0.605$ & $1.33 \pm 0.635$ & 0.488 & 0.626 \\
\hline Injection volume of bone cement in a single vertebrae $(\mathrm{mL})$ & $4.645 \pm 1.1732$ & $4.58 I \pm 0.6974$ & -1.000 & 0.318 \\
\hline Leakage rate of bone cement (\%) & & & 1.699 & 0.192 \\
\hline Yes & $115(31.8)$ & $522(28.4)$ & & \\
\hline No & $247(68.2)$ & $1318(7 \mid .6)$ & & \\
\hline Smoking (\%) & & & 7.825 & 0.005 \\
\hline Yes & $55(15.2)$ & $187(10.2)$ & & \\
\hline No & $307(84.8)$ & $1653(89.8)$ & & \\
\hline Alcohol consumption (\%) & & & 7.098 & 0.008 \\
\hline Yes & $46(12.7)$ & $153(8.3)$ & & \\
\hline No & $316(87.3)$ & $1687(91.7)$ & & \\
\hline Diabetes (\%) & & & 8.511 & 0.004 \\
\hline Yes & $109(30.1)$ & $422(22.9)$ & & \\
\hline No & $253(69.9)$ & $1418(77.1)$ & & \\
\hline Hypertension (\%) & & & 1.526 & 0.217 \\
\hline Yes & $106(29.3)$ & $48 I(26.1)$ & & \\
\hline No & $256(70.7)$ & 1359 (73.9) & & \\
\hline Coronary heart disease (\%) & & & 0.207 & 0.649 \\
\hline Yes & $77(21.3)$ & $372(20.2)$ & & \\
\hline No & $285(78.7)$ & I468 (79.8) & & \\
\hline Chronic obstructive pulmonary disease (\%) & & & 0.995 & 0.319 \\
\hline Yes & $49(13.5)$ & $287(15.6)$ & & \\
\hline No & $313(86.5)$ & $1553(84.4)$ & & \\
\hline Postoperative exercise (\%) & & & 200.444 & 0.000 \\
\hline Yes & $171(47.2)$ & $1507(8 \mid .9)$ & & \\
\hline No & $191(52.8)$ & $333(18.1)$ & & \\
\hline Postoperative osteoporosis treatment (\%) & & & 44.125 & 0.000 \\
\hline Yes & $77(21.3)$ & $730(39.7)$ & & \\
\hline No & $285(78.7)$ & $1110(60.3)$ & & \\
\hline
\end{tabular}

greater bony absorption than bone formation. This imbalance in bone homeostasis increases bone brittleness. ${ }^{10,11}$ The risk of postmenopausal osteoporosis increases the risk of vertebral fracture by three to four-fold compared with men of the same age. ${ }^{12}$ Therefore, elderly patients, especially females, should be informed of the high risk of refracture after surgery. Clinicians also need to be vigilant and should consider shortening the review period, 
Table 2 Multivariate Logistic Regression Analysis of New Vertebral Fracture After Vertebroplasty

\begin{tabular}{|l|l|l|l|l|l|l|l|}
\hline Variable & $\begin{array}{l}\text { Partial Regression } \\
\text { Coefficient }\end{array}$ & $\begin{array}{l}\text { Standard } \\
\text { Error }\end{array}$ & $\begin{array}{l}\text { Wald } \\
\text { value }\end{array}$ & \multicolumn{2}{l}{ P value } & $\begin{array}{l}\text { Odds } \\
\text { Ratio }\end{array}$ & \multicolumn{2}{l}{$\begin{array}{l}\text { Odds Ratio } \\
\mathbf{9 5} \text { Cl }\end{array}$} & Lower & Upper \\
\hline Age (yr) & 0.193 & 0.016 & 141.264 & 0.000 & 1.212 & 1.174 & 1.252 \\
\hline Sex & 0.651 & 0.168 & 15.008 & 0.000 & 1.917 & 1.379 & 2.665 \\
\hline Smoking & 0.431 & 0.193 & 4.989 & 0.026 & 1.538 & 1.054 & 2.245 \\
\hline Alcohol consumption & 0.075 & 0.208 & 0.126 & 0.719 & 1.078 & 0.717 & 1.620 \\
\hline Diabetes & 0.650 & 0.146 & 19.751 & 0.000 & 1.915 & 1.438 & 2.551 \\
\hline Postoperative exercise & -1.516 & 0.134 & 127.709 & 0.000 & 0.220 & 0.169 & 0.286 \\
\hline $\begin{array}{l}\text { Postoperative osteoporosis } \\
\text { treatment }\end{array}$ & -0.884 & 0.155 & 32.340 & 0.000 & 0.413 & 0.305 & 0.560 \\
\hline
\end{tabular}

Abbreviation: $\mathrm{Cl}$, confidence interval.

prolonging the follow-up period, and timely assessment of any new postoperative back pain.

\section{Lifestyle Factors}

There are approximately 1.3 billion smokers worldwide. ${ }^{13}$ Tobacco contains upto 1000 kinds of harmful substances, among which nicotine has been proven to have a malignant effect on bone. ${ }^{14}$ In particular, nicotine affects the bones' blood supply and ability to heal. ${ }^{15}$ CostaRodrigues et $\mathrm{al}^{16}$ showed that nicotine in smokers' plasma could act directly on osteoclasts and induce differentiation and worsening of osteoporosis. Joehanes et al ${ }^{17}$ conducted genetic tests on 15,907 blood samples and showed that harmful substances in tobacco could cause DNA methylation; this affects the regeneration and transformation of bone tissue, causing or aggravating osteoporosis. The degree of DNA methylation is much higher in smokers than in non-smokers. ${ }^{17}$ In our study, smoking was an independent risk factor for new vertebral fracture development after PVP. Therefore, patients should be encouraged to stop smoking postoperatively. Although females are less likely to smoke than males, they are more vulnerable to the effects of secondhand smoke. Kim et $\mathrm{al}^{18}$ showed that long-term exposure to secondhand smoke could increase the incidence of osteoporosis in female non-smokers. Therefore, if a patient's family member is a smoker, they too should be advised to stop smoking. Kiyota et $\mathrm{al}^{19}$ confirmed that the disruption of bone homeostasis induced by smoking could recover gradually after smoking cessation. Therefore, stopping smoking postoperatively will help prevent the occurrence of new fractures.

Studies have shown that alcohol intake can affect osteoporosis development. Alcohol is metabolized to

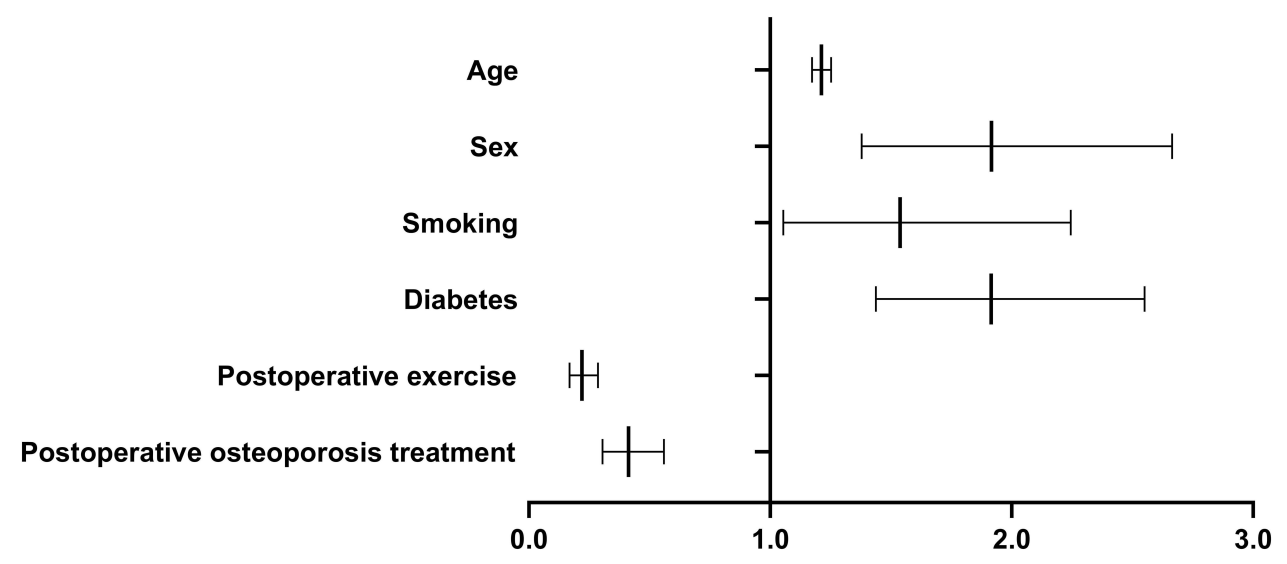

Figure I Risk factores of new vertebral fracture after vertebroplasty. 
acetaldehyde, which inhibits osteoblasts. ${ }^{19}$ However, despite there being a significant difference in the proportion of alcohol drinkers in the fracture group than in the non-fracture group in univariate analysis, this was not significant in multivariate analysis. This could be because we did not measure the amount of alcohol consumed. Previous studies have shown that ethanol has a dosedependent effect on bone remodeling, ${ }^{20}$ and individuals have different degrees of tolerance to alcohol, which may have biased our results.

The incidence of diabetes is increasing yearly. In addition to damaging the blood vessels and nerves, diabetes is harmful to the bones. Botolin et $\mathrm{al}^{21}$ found that both type 1 and type 2 diabetes can affect bone remodeling and stem cell differentiation, thus, affecting bone strength and leading to changes in bone density and structure. A prospective study by Schwartz et $\mathrm{al}^{22}$ showed that whether due to insufficient insulin or insulin resistance, excessive blood glucose level impairs the osteoblast's ability to synthesize bone due to reduced osteocalcin, thus, aggravating osteoporosis. In this study, diabetes was a risk factor for new vertebral fracture after PVP (OR=1.915, 95\% CI=1.438-2.551, $\mathrm{P}<0.0001)$. Therefore, it is important for diabetic patients to maintain good control of their blood glucose level postoperatively to prevent the development of new fractures. Viollet et $\mathrm{al}^{23}$ found that drugs, such as metformin, can improve insulin sensitivity and promote the activity of osteoblasts, thus, increasing bone density and delaying the progression of osteoporosis. Therefore, postoperative PVP patients and diabetes mellitus can delay or prevent the progression of osteoporosis and prevent new vertebral fracture development by achieving good blood glucose control.

\section{Postoperative Exercise and Osteoporosis Treatment}

At present, most studies have confirmed that at least $3 \mathrm{~h}$ of physical activity per week is beneficial to the improvement of bone mineral density. ${ }^{24-26}$ The main cause of OVCFs is falling. Elderly patients are more prone to falls due to nerve and muscle degeneration, resulting in reduced coordination. Additionally, insufficient physical activity is an important risk factor leading to bone loss. Tinetti et $\mathrm{al}^{27}$ showed that being sedentary with insufficient exercise significantly increases bone loss. To avoid new vertebral fractures following PVP, physical activity is indispensable to the recovery process. Sufficient and appropriate physical activity can effectively restore and strengthen skeletal muscle, prevent muscle atrophy, improve reaction times, maintain stability and coordination, and thus, reduce the risk of falls. Sherrington et $\mathrm{al}^{28}$ analyzed almost 19,500 osteoporotic participants and showed that postoperative exercise could effectively reduce the incidence of falls in the elderly; indeed, in our study, postoperative exercise $(\mathrm{OR}=0.220$, $95 \% \mathrm{CI}=0.169-0.286, \mathrm{P}<0.0001)$ was a protective factor for new vertebral fracture development after PVP, indicating that $30 \mathrm{~min}$ of exercise at least four times a week was beneficial. However, some patients cannot adhere to an exercise regimen after hospital discharge due to a fear of repeat falls. Doctors should educate patients on the importance of postoperative physical activity and encourage them to participate in sports and exercise. A prospective study of patients with spinal fracture conducted by Deng et al $^{29}$ showed that postoperative exercise to strengthen back muscles could effectively improve physical function, relieve pain, maintain bone density, and greatly reduce the risk of re-fracture. Howe et $\mathrm{al}^{30}$ followed up 4320 patients to assess the impact of exercise on bone mineral density over time. Compared with those who did not exercise, the rate of postoperative bone loss in patients who exercised was reduced. This further supports the findings of our study.

Osteoporosis can be caused by many factors, including nerve and endocrine factors; however, its main cause is bone loss. Once this starts, it is difficult to prevent or reverse progression by solely relying on the patient's regulatory mechanisms. ${ }^{8}$ This is compounded by the insidious onset of osteoporosis, lack of early clinical signs, ${ }^{2}$ and poor awareness, implying that the potential for harm is significant. Osteoporosis medication can effectively prevent or even reverse bone loss. ${ }^{31}$ Hoff et al ${ }^{32}$ screened 28,461 volunteers and analyzed the effects of osteoporosis medication on fracture incidence, which was significantly lower in the treated than in the untreated group, thus, highlighting the importance of medical interventions for bone loss. In our study, postoperative osteoporosis treatment $(\mathrm{OR}=0.413,95 \% \mathrm{CI}=0.305-0.560, \mathrm{P}<0.0001)$ was a protective factor for new vertebral fractures. We used calcitonin and bisphosphonates to treat osteoporosis. Their main function is to inhibit osteoclast activity and reduce bone resorption, effectively preventing bone loss. ${ }^{33,34} \mathrm{Saag}$ et $\mathrm{al}^{35}$ showed that the rate of bone loss was reduced after the administration of bisphosphonates. Therefore, to prevent new vertebral fractures after PVP, clinicians should inform patients of the harms of osteoporosis, outline preventative measures, and recommend postoperative osteoporosis treatment. 


\section{Limitations}

The results obtained from our univariate and multivariate analyses reinforce the previous suggestions in smaller series, which, however, reported a higher incidence of adjacent fracture than what we observed ( $20 \%$ vs $16 \%$ ). The difference may have been caused by the difference in sample size. ${ }^{36}$ This was a single-center retrospective study, and only patients who underwent PVP were included. We chose not to include patients with percutaneous kyphoplasty because their postoperative outcomes are different from those of PVP patients. In addition, the method of anesthesia employed may have impacted postoperative re-fracture rates. Postoperative exercise methods were not further detailed; thus, we could not explore whether different kinds of physical activity would have different impacts on bone loss. In terms of lifestyle factors, smoking and alcohol consumption were not included in the further analysis for specific dose-effect relationships. Only calcitonin and bisphosphonate drugs were included, and other drugs were excluded from the analysis. Hence, further studies with larger samples, multiple risk factors, and detailed classifications are needed.

\section{Conclusion}

Elderly patients, females, and those with a history of smoking and diabetes are at higher risk of new vertebral fracture development after PVP. Patients should be advised to stop smoking, to reduce alcohol consumption, and to achieve good blood glucose control after PVP. In addition, they should be encouraged to engage in adequate levels of physical activity and to adhere to osteoporosis treatments to prevent new vertebral fractures.

\section{Abbreviations}

$\mathrm{CI}$, confidence interval; MRI, magnetic resonance imaging; OR, odds ratio; OVCF, osteoporotic vertebral compression fracture; PVP, percutaneous vertebroplasty; BMD, bone mineral density.

\section{Data Sharing Statement}

Data will be made available upon reasonable request to the corresponding author.

\section{Ethics Approval and Informed Consent}

The study was conducted in agreement with the Declaration of Helsinki and was approved by the Ethics Committee of the Honghui Hospital in China (201312002). All participants gave written informed consent.

\section{Acknowledgments}

We would like to thank the patients for their willingness to participate in our study.

\section{Author Information}

Zi-Long Zhang Men, born in 1994, is a spinal surgeon in Honghui Hospital engaged in clinical research related to spinal surgery.

\section{Author Contributions}

All authors have agreed on the journal to which the article will be submitted. Additionally, all authors have reviewed and agreed on all versions of the article before submission and during revision, the final version accepted for publication, and any significant changes introduced during proofreading.

\section{Funding}

We would like to thank Chinese national natural science foundation (No.81830077 for Ding-Jun Hao) for providing the grant.

\section{Disclosure}

The authors declared no potential conflicts of interest with respect to the research, authorship, and/or publication of this article.

\section{References}

1. Compston JE, McClung MR, Leslie WD. Osteoporosis. Lancet. 2019;393(10169):364-376. doi:10.1016/S0140-6736(18)32112-3

2. Sambrook P, Cooper C. Osteoporosis. Lancet. 2006;367 (9527):2010-2018. doi:10.1016/S0140-6736(06)68891-0

3. Galibert P, Deramond H, Rosat P, Le Gars D. Note préliminaire sur le traitement des angiomes vertébraux par vertébroplastie acrylique percutanée [Preliminary note on the treatment of vertebral angioma by percutaneous acrylic vertebroplasty]. Neurochirurgie. 1987;33 (2):166-168. French.

4. Fehlings MG. The safety of percutaneous vertebroplasty and kyphoplasty. J Neurosurg Spine. 2009;11(5):605-6. doi:10.3171/ 2009.6.SPINE09359

5. Feng L, Feng C, Chen J, Wu Y, Shen JM. The risk factors of vertebral refracture after kyphoplasty in patients with osteoporotic vertebral compression fractures: a study protocol for a prospective cohort study. BMC Musculoskelet Disord. 2018;19(1):195. doi:10.1186/ s12891-018-2123-6

6. Lee BG, Choi JH, Kim DY, Choi WR, Lee SG, Kang CN. Risk factors for newly developed osteoporotic vertebral compression fractures following treatment for osteoporotic vertebral compression fractures. Spine J. 2019;19(2):301-305. doi:10.1016/j.spinee.2018.06.347

7. Eichler MC, Spross C, Ewers A, Mayer R, Külling FA. Prophylactic adjacent-segment vertebroplasty following kyphoplasty for a single osteoporotic vertebral fracture and the risk of adjacent fractures: a retrospective study and clinical experience. J Neurosurg Spine. 2016;25(4):528-534. doi:10.3171/2016.2.SPINE15907 
8. Kanis JA, Cooper C, Rizzoli R, et al. Scientific advisory board of the European society for clinical and economic aspects of osteoporosis (ESCEO) and the committees of scientific advisors and national societies of the international osteoporosis foundation (IOF). European guidance for the diagnosis and management of osteoporosis in postmenopausal women. Osteoporos Int. 2019;24(1):23-57. doi:10.1007/s00198-018-4704-5

9. Warden SJ, Carballido-Gamio J, Avin KG, et al. Adaptation of the proximal humerus to physical activity: a within-subject controlled study in baseball players. Bone. 2019;121:107-115. doi:10.1016/j. bone.2019.01.008

10. Almeida M, Laurent MR, Dubois V, et al. Estrogens and androgens in skeletal physiology and pathophysiology. Physiol Rev. 2017;97 (1):135-187. doi:10.1152/physrev.00033.2015

11. Lee EJ, Kim JL, Kim YH, Kang MK, Gong JH, Kang YH. Phloretin promotes osteoclast apoptosis in murine macrophages and inhibits estrogen deficiency-induced osteoporosis in mice. Phytomedicine. 2014;21(10):1208-1215. doi:10.1016/j.phymed.2014.04.002

12. Eastell R, Szulc P. Use of bone turnover markers in postmenopausal osteoporosis. Lancet Diabetes Endocrinol. 2017;5(11):908-923. doi:10.1016/S2213-8587(17)30184-5

13. Clearing the smoke. Nat Neurosci. 2014;17(8):1013. doi:10.1038/ nn. 3777

14. Pereira ML, Carvalho JC, Peres F, Fernandes MH. Effect of nicotine in matrix mineralization by human bone marrow and Saos-2 cells cultured on the surface of plasma-sprayed titanium implants. J Biomed Mater Res A. 2009;88(1):84-93. doi:10.1002/jbm.a.31873

15. Chang CJ, Jou IM, Wu TT, Su FC, Tai TW. Cigarette smoke inhalation impairs angiogenesis in early bone healing processes and delays fracture union. Bone Joint Res. 2020;9(3):99-107. doi:10.1302/20463758.93.BJR-2019-0089.R1

16. Costa-Rodrigues J, Rocha I, Fernandes MH. Complex osteoclastogenic inductive effects of nicotine over hydroxyapatite. $J$ Cell Physiol. 2018;233(2):1029-1040. doi:10.1002/jcp.25956

17. Joehanes R, Just AC, Marioni RE, et al. Epigenetic signatures of cigarette smoking. Circ Cardiovasc Genet. 2016;9(5):436-447. doi:10.1161/CIRCGENETICS.116.001506

18. Kim KH, Lee CM, Park SM, et al. Secondhand smoke exposure and osteoporosis in never-smoking postmenopausal women: the fourth Korea national health and nutrition examination survey. Osteoporos Int. 2013;24(2):523-532. doi:10.1007/s00198-012-1987-9

19. Kiyota Y, Muramatsu H, Sato Y, et al. Smoking cessation increases levels of osteocalcin and uncarboxylated osteocalcin in human sera. Sci Rep. 2020;10(1):16845. doi:10.1038/s41598-020-73789-4

20. Maurel DB, Boisseau N, Benhamou CL, Jaffre C. Alcohol and bone: review of dose effects and mechanisms. Osteoporos Int. 2012;23 (1):1-16. doi:10.1007/s00198-011-1787-7

21. Botolin S, Faugere MC, Malluche H, Orth M, Meyer R, McCabe LR. Increased bone adiposity and peroxisomal proliferator-activated receptor-gamma2 expression in type I diabetic mice. Endocrinology. 2005;146(8):3622-3631. doi:10.1210/en.2004-1677

22. Schwartz AV, Sellmeyer DE, Ensrud KE, et al.; Study of Osteoporotic Features Research Group. Older women with diabetes have an increased risk of fracture: a prospective study. J Clin Endocrinol Metab. 2001;86(1):32-38. doi:10.1210/jcem.86.1.7139
23. Viollet B, Guigas B, Sanz Garcia N, Leclerc J, Foretz M, Andreelli F. Cellular and molecular mechanisms of metformin: an overview. Clin Sci. 2012;122(6):253-270. doi:10.1042/CS20110386

24. Martyn-St James M, Carroll S. Meta-analysis of walking for preservation of bone mineral density in postmenopausal women. Bone. 2008;43(3):521-531. doi:10.1016/j.bone.2008.05.012

25. Faber MJ, Bosscher RJ, Chin A, Paw MJ, van Wieringen PC. Effects of exercise programs on falls and mobility in frail and pre-frail older adults: a multicenter randomized controlled trial. Arch Phys Med Rehabil. 2006;87(7):885-896. doi:10.1016/j.apmr.2006.04.005

26. Briggs AM, Greig AM, Wark JD. The vertebral fracture cascade in osteoporosis: a review of aetiopathogenesis. Osteoporos Int. 2007;18 (5):575-584. doi:10.1007/s00198-006-0304-x

27. Tinetti ME, Speechley M, Ginter SF. Risk factors for falls among elderly persons living in the community. $N$ Engl J Med. 1988;319 (26):1701-1707. doi:10.1056/NEJM198812293192604

28. Sherrington C, Michaleff ZA, Fairhall N, et al. Exercise to prevent falls in older adults: an updated systematic review and meta-analysis. Br J Sports Med. 2017;51(24):1750-1758. doi:10.1136/bjsports2016-096547

29. Deng D, Lian Z, Cui W, Liang H, Xiao L, Yao G. Function of low back muscle exercise: preventive effect of refracture analysis of postoperative vertebral fractures. Orthopade. 2019;48(4):337-342. doi:10.1007/s00132-018-3577-9

30. Howe TE, Shea B, Dawson LJ, et al. Exercise for preventing and treating osteoporosis in postmenopausal women. Cochrane Database Syst Rev. 2011;7:CD000333. doi:10.1002/14651858.CD000333.pub2

31. Iolascon G, de Sire A, Calafiore D, et al. Multifactorial assessment of risk of falling in 753 post-menopausal women: a multicenter cross-sectional study by the Italian group for the study of metabolic bone diseases. Clin Interv Aging. 2020;15:1077-1084. doi:10.2147/ CIA.S257304

32. Hoff M, Skurtveit S, Meyer HE, et al. Anti-osteoporosis drug use: too little, too much, or just right? The HUNT study, Norway. Osteoporos Int. 2018;29(8):1875-1885. doi:10.1007/s00198-018-4560-3

33. Tsukamoto M, Menuki K, Murai T, et al. Elcatonin prevents bone loss caused by skeletal unloading by inhibiting preosteoclast fusion through the unloading-induced high expression of calcitonin receptors in bone marrow cells. Bone. 2016;85:70-80. doi:10.1016/j. bone.2016.01.025

34. Editorial Office of Osteoporosis International. Correction to: over half of seniors who start oral bisphosphonate therapy are exposed for 3 or more years: novel rolling window approach and patterns of use. Osteoporos Int. 2021;32(4):803. doi:10.1007/s00198-021-05883-w

35. Saag K, Cosman F, De Villiers T, et al. Early changes in bone turnover and bone mineral density after discontinuation of long-term oral bisphosphonates: a post hoc analysis. Osteoporos Int. 2021. doi:10.1007/s00198-020-05785-3

36. Martikos K, Greggi T, Faldini C, et al. Osteoporotic thoracolumbar compression fractures: long-term retrospective comparison between vertebroplasty and conservative treatment. Eur Spine J. 2018;27 (Supp12):244-247. doi:10.1007/s00586-018-5605-1
Clinical Interventions in Aging

\section{Publish your work in this journal}

Clinical Interventions in Aging is an international, peer-reviewed journal focusing on evidence-based reports on the value or lack thereof of treatments intended to prevent or delay the onset of maladaptive correlates of aging in human beings. This journal is indexed on PubMed Central, MedLine, CAS, Scopus and the Elsevier
Bibliographic databases. The manuscript management system is completely online and includes a very quick and fair peer-review system, which is all easy to use. Visit http://www.dovepress.com/ testimonials.php to read real quotes from published authors. 